\title{
Oral Sub mucous Fibrosis and Tobacco Use among Slum Dwellers of Bhopal City, India
}

\author{
Binu Santha ${ }^{1 *}$, Vrinda Saxena ${ }^{2}$, Manish Jain ${ }^{3}$, Naveen S Yadav ${ }^{4}$, Vidhatri Tiwari ${ }^{5}$ and Utkarsh Tiwari ${ }^{6}$ \\ ${ }^{1}$ Public Health Dentistry, Rotorua, New Zealand \\ 2Department of Public Health Dentistry, People's Dental Academy, People's University, Bhopal, M.P., India \\ ${ }^{3}$ Department of Public Health Dentistry, SMBT Institute of Dental Sciences and Research Centre, Nasik, India \\ ${ }^{4}$ Department of Prosthodontics and Crown \& Bridge, People's Dental Academy, Bhopal, M.P., India \\ ${ }^{5}$ Department of Public Health Dentistry, Manasarovar Dental College, Bhopal, India \\ ${ }^{6}$ Department of Pedodontics and Preventive Dentistry, Manasarovar Dental College, Bhopal, India
}

\begin{abstract}
Background: Oral sub mucous fibrosis is a chronic insidious disease of the oral mucosa. Oral Sub mucous fibrosis (OSMF) is a pre-cancerous condition predominantly seen among betel quid chewers, areca nut chewing, tobacco smoking and chewing. The slum dwellers are more prone to chewing habits. Hence this study was undertaken to analyze the tobacco use and its association with OSMF among the slum dwellers of Bhopal City.
\end{abstract}

Objective: To study the prevalence of oral sub mucous fibrosis and its relation with tobacco use among slum dwellers in Bhopal city, India.

Materials and Methods: The study was conducted to evaluate the tobacco related practices amongst the slum dwellers and its impact on oral health. The study included residence of chola road. A self-designed printed questionnaire form was used to collect the data. The questions included demoFigureic details, the habit of tobacco consumption and the frequency of tobacco consumption.

Results: Tobacco habit is common among the slum dwellers of Bhopal City and it does not have a significant association with the occurrence of Oral Sub mucous Fibrosis in this population $(p>0.05)$.

Conclusions: The habit of tobacco consumption has an impact on the occurrence of OSMF among the slum dwellers of Bhopal City.

Keywords: Oral sub mucous fibrosis; Tobacco consumption; Slum dwellers; Pre-cancerous condition

\section{Introduction}

Oral sub mucous fibrosis is a chronic insidious disease of the oral mucosa characterized by loss of mucosal elasticity and excessive fibrosis. It is always associated with juxta epithelial inflammation and progressive hyalinization of lamina propria [1-3].

It was described by Schwartz in 1952 as a fibrosing condition of the mouth in 5 Indian women from Kenya for which he coined the term "Atrophica idiopathica tropica mucosae oris" [4]

Oral Sub mucous fibrosis (OSMF) is a pre-cancerous condition predominantly seen among betel quid chewers. It has characteristic clinical presentation depending on the stage of the disease, but majority of patients with OSMF have intolerance to spicy food, roughness of oral mucosa, and different degrees of difficulty in opening the mouth.

OSMF is a well recognized potentially malignant condition in the oral cavity \& the transformation rate is as high as $7.6 \%$ over a period of ten year have been reported from India [5].

The etiology of oral sub mucous fibrosis is multifactorial. The etiological factors include local irritants such as spice consumption, areca nut chewing, tobacco smoking and chewing. Systemic factors include anemia (iron deficiency), vitamin deficiencies (B-complex and folate) together with the malnourished state (protein deficiency), genetic predisposition to the disease and autoimmunity.

Diverse agents including lime, tobacco, catechu, cloves, saffaron, and leaf of piper betel leaves may form a part of formulation [6]. A study was undertaken to evaluate the effect of tobacco related practices on oral health of tribes in Central India. The use of smokeless tobacco, gutkha \& associated products is on the rise amongst the younger generation making oral precancer \& cancer a public health concern. In central India $80 \%$ of head and neck cancers are found in the oral cavity and oropharynx. Oral squamous cell carcinoma comprises over $90 \%$ of the malignancies, which begin as inflammatory lesions such as leukoplakia, erythroplakia and erythroleukoplakia [7]. Notably, oral cancer is one of the few cancers whose survival rate has not improved over 30 years, while during the past three decades a $60 \%$ increase in oral cancer in adults under the age of 40 has been $\mathrm{d}$ Oral pre-cancer (Oral Submucous Fibrosis (OSMF) \& Leukoplakia) and cancers are caused by gene environment interactions, and large consumption of tobacco and/or areca nut amongst other factors In the area under study, "Tambaku" is the most commonly consumed form of smokeless tobacco [8]. Smokeless forms of tobacco, due to their placement in the oral cavity, increase the concentration of carcinogens and the failure to clean the carcinogens from the surface, augment this effect. Tobacco when added to areca nut, lime, flavouring agents and catechu is termed "Gutkha"; which is a commercially available product within India $[9,10]$. Working towards the mitigation of factors affecting tobacco menace at the individual level as well as at the community level should

*Corresponding author: Binu Santha, M.D.S., Public Health Dentistry, Rotorua, New Zealand, Tel: + 6422 0366326; E-mail: binusantha@gmail.com

Received September 01, 2017; Accepted September 11, 2017; Published September 19, 2017

Citation: Santha B, Saxena V, Jain M, Yadav NS, Tiwari V, et al. (2017) Oral Sub mucous Fibrosis and Tobacco Use among Slum Dwellers of Bhopal City, India. Dentistry 7: 455. doi:10.4172/2161-1122.1000455

Copyright: $\odot 2017$ Santha B, et al. This is an open-access article distributed under the terms of the Creative Commons Attribution License, which permits unrestricted use, distribution, and reproduction in any medium, provided the original author and source are credited. 
be implemented as a part of a long term commitment to safeguard public health. Anti- tobacco initiatives are thus warranted documented.

This study aimed to assess the tobacco related practices and the related oral health amongst the inhabitants of Chola road, Bhopal. The higher prevalence of tobacco use (smokeless and smoked) and associated tobacco product consumption by the younger population is an issue of significant concern and prompted this study to be conducted.

\section{Objective}

1. To evaluate the prevalence of oral sub mucous fibrosis and its relation with tobacco use among slum dwellers in Bhopal.

2. To evaluate the duration for which there was tobacco consumption amongst the people of slum.

3. To analyze the prevalence of other disease related to tobacco use.

4. To find out all the lesions associated with oral submucous fibrosis.

\section{Methodology}

This study was conducted to evaluate the tobacco related practices amongst slum dwellers of Bhopal city and its impact on Oral sub mucous fibrosis. Source of Data were the slum dwellers of Chola Road, Bhopal city. Sampling frame included the slum dwellers in the age group of 20-60 years and sample design was convenience sampling and sample size included 71 subjects. Ethical clearance was taken from the People's Dental Academy, Bhopal. Permissions for conducting this study were taken from the municipality authorities.

\section{Inclusion criteria}

1. Subjects in the age group of 20-60 years

2. Subjects with the habit of tobacco use

3. Subjects present on the day of the survey

\section{Exclusion criteria}

1. Subjects absent on the day of survey

2. Subjects who do not have the habit of smoking or chewing tobacco.

A structured questionnaire was used for collection of data which included the demoFigureic factors of Gender, education and Occupation and Self-assessment of oral health status, Dietary habits and Lifestyles like smoking and tobacco chewing. The questionnaires were completed by the subjects themselves. The questionnaire was originally formulated in English, subsequently translated into Hindi, and then retranslated into English.

The collected data were coded, and a statistical analysis was carried out by using Microsoft Excel 2003 and Statistical Package of Social Science (SPSS 12). Description and analysis of the data was carried out by frequency distributions. Level of significance was considered as 0.05 .

\section{Results}

This study was conducted among the slum dwellers of Bhopal city to evaluate the tobacco related practices amongst the slum dwellers and its impact on oral health. Among the study subject out of a total of 71 participant $34(47.9 \%)$ were in the age group of 20 -30 years, $9(12.7 \%)$ were $31-40$ years, 15 (21.1\%) were $41-50$ years and 13 (18.3\%) were 51-
60 years (Table 1 and Figure 1). Out of the total 69 (97.2\%) were males and $02(2.8 \%)$ were only females (Table 2 and Figure 2).

Educational distribution among the study subject show that out of a total of 71 participants, 19 (26.4\%) had primary education, 18 (25\%) secondary, higher secondary 18 (25\%) and uneducated were $16(22.6 \%)$ (Table 3 and Figure 3).

Occupational distribution among the study subject show that out of a total of 71 participant Labourers, Driver, Bus Conductor comprised of 38 (52.7\%), Carpenter, Shopkeeper, Cobbler, Vegetable Vendor were 11(15.3\%), Farmer, Watchman, Sweeper were $8(11.2 \%)$ and Student or no occupation were 15 (20.8\%)(Table 4 and Figure 4 ).

On evaluating the substance addiction pattern of chewing tobacco among the study subjects, it was observed that out of a total of 71 participant, the habit of smoking was seen among 17 (23.6\%), chewing among $18(25 \%)$, snuffing in $6(8.4 \%)$, and smoking \& chewing habit in 30 (43\%) (Table 5 and Figure 5).

Among the total of 71 study participants, it was observed that 45 (63.3\%) had felt burning sensation in their mouth (Table 6). In a total of 71 study subjects, 37 (52.1\%) had difficulty in mouth opening and $36(50.7 \%)$ had difficulty in eating hot and spicy food (Table 7$)$. On analysing the presence of other symptoms associated with Oral Sub mucous Fibrosis, it was observed that out of a total of 71 participant ulceration was observed among $54(76.1 \%)$, leathery surface texture among 4 (5.5\%), burning sensation among $10(14.1 \%)$ and all the symptoms combined among 03 (4.3\%) (Table 8 and Figure 6). Pearson's Correlation between Tobacco habit and the Oral Sub Mucous fibrosis was found to -0.124 which was not statistically significant $(\mathrm{p}=0.305)$ (Table 9).

Table 1: Frequency distribution of study subjects according to age.

\begin{tabular}{|c|c|c|}
\hline Age & Number & $\%$ \\
\hline $20-30$ Years & 34 & $47.90 \%$ \\
\hline $31-40$ Years & 9 & $12.70 \%$ \\
\hline $41-50$ Years & 15 & $21.10 \%$ \\
\hline $51-60$ Years & 13 & $18.30 \%$ \\
\hline Total & 71 & $100 \%$ \\
\hline
\end{tabular}

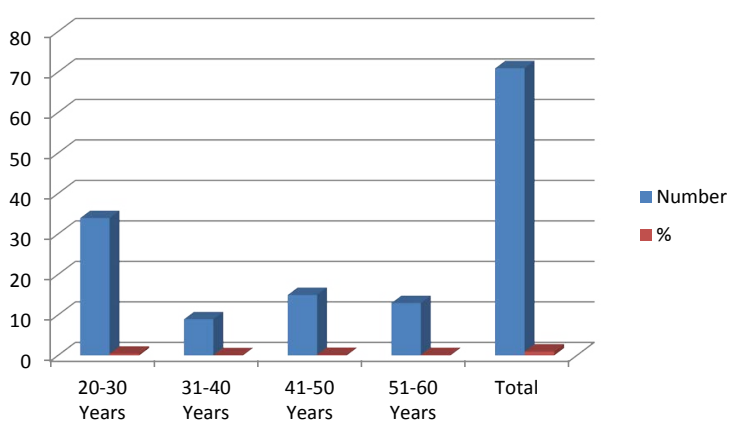

Figure 1: Bar Chart showing the age distribution among the study subjects.

Table 2: Frequency Distribution of study subjects according to Gender.

\begin{tabular}{|c|c|c|}
\hline Gender & Number & $\%$ \\
\hline Male & 69 & $97.20 \%$ \\
\hline Female & 2 & $2.80 \%$ \\
\hline Total & 71 & $100 \%$ \\
\hline
\end{tabular}


Citation: Santha B, Saxena V, Jain M, Yadav NS, Tiwari V, et al. (2017) Oral Sub mucous Fibrosis and Tobacco Use among Slum Dwellers of Bhopal City, India. Dentistry 7: 455. doi:10.4172/2161-1122.1000455

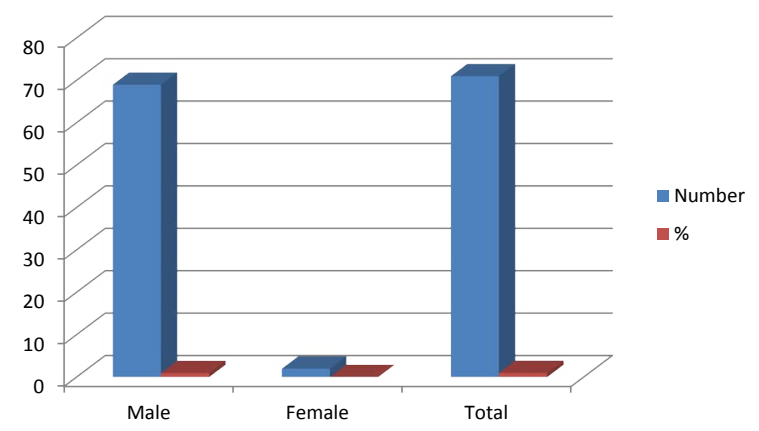

Figure 2: Bar Chart showing the gender distribution among the study subjects.

Table 3: Frequency distribution of study subjects according to education.

\begin{tabular}{|c|c|c|}
\hline Education & Number & $\%$ \\
\hline Primary & 19 & $26.40 \%$ \\
\hline Secondary & 18 & $25 \%$ \\
\hline Higher secondary & 18 & $25 \%$ \\
\hline Non educated & 16 & $22.60 \%$ \\
\hline Total & 71 & $100 \%$ \\
\hline
\end{tabular}

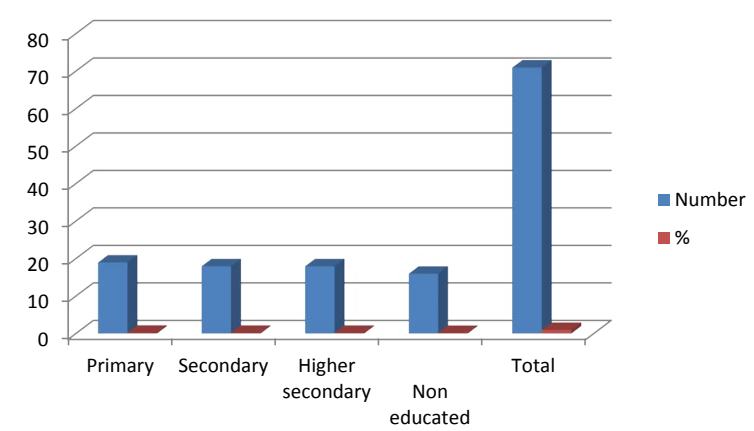

Figure 3: Bar Chart showing the educational distribution among the study subjects.

Table 4: Frequency distribution of study subjects according to occupation.

\begin{tabular}{|c|c|c|}
\hline Occupation & Number & $\%$ \\
\hline Labourer, Driver, Bus Conductor & 38 & $52.70 \%$ \\
\hline $\begin{array}{c}\text { Carpenter, Shopkeeper, Cobbler, Vegetable } \\
\text { Vendor }\end{array}$ & 11 & $15.30 \%$ \\
\hline Farmer, Watchman, Sweeper & 8 & $11.20 \%$ \\
\hline Student, No Occupation & 15 & $20.80 \%$ \\
\hline Total & 71 & $100 \%$ \\
\hline
\end{tabular}

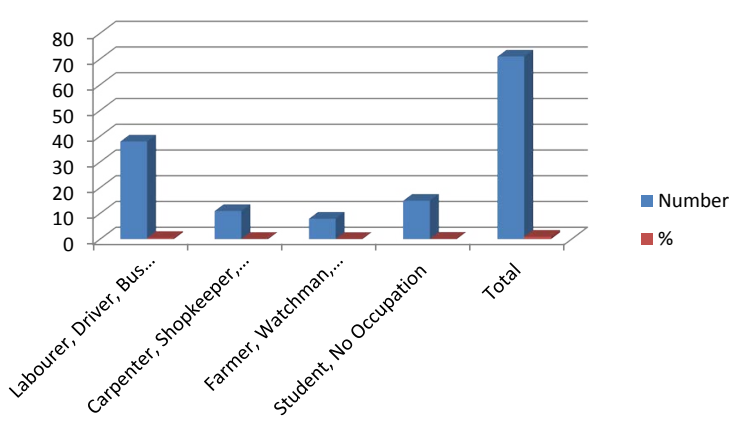

Figure 4: Bar Chart showing the Occupational distribution among the study subjects.
Table 5: Frequency distribution of study subjects according to substance addiction.

\begin{tabular}{|c|c|c|}
\hline Substance & Number & $\%$ \\
\hline Addiction & 17 & $23.60 \%$ \\
\hline Smoking & 18 & $25 \%$ \\
\hline Chewing & 6 & $8.40 \%$ \\
\hline Snuffing & 0 & $0 \%$ \\
\hline Tobacco manjan & 30 & $43 \%$ \\
\hline Smoking \& chewing & 71 & $100 \%$ \\
\hline Total & & \\
\hline
\end{tabular}

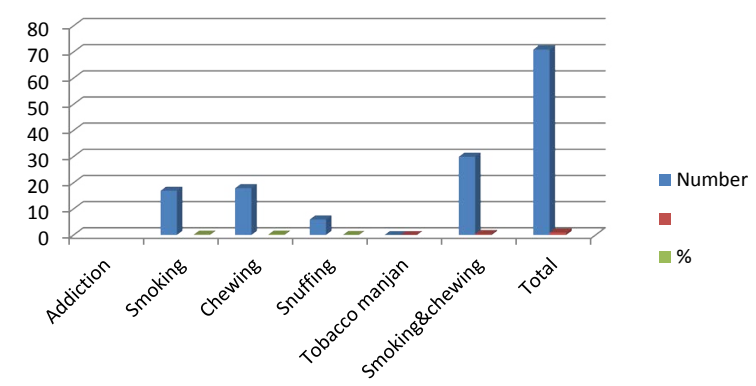

Figure 5: Bar Chart showing the Substance addiction among the study subjects.

Table 6: Frequency distribution of study subjects according to burning sensation in mouth.

\begin{tabular}{|c|c|c|}
\hline Burning sensation & Number & $\%$ \\
\hline Yes & 45 & $63.30 \%$ \\
\hline No & 26 & $36.70 \%$ \\
\hline Total & 71 & $100 \%$ \\
\hline
\end{tabular}

Table 7: Frequency distribution of study subjects according to difficulty in mouth opening and eating hot and spicy foods.

\begin{tabular}{|c|c|c|}
\hline Reduction/hindrance & Number & $\%$ \\
\hline Yes & 37 & $52.10 \%$ \\
\hline No & 34 & $47.90 \%$ \\
\hline Total & 71 & $100 \%$ \\
\hline Ability to eat hot \& spicy foods & & \\
\hline Yes & 36 & $50.70 \%$ \\
\hline No & 35 & $49.30 \%$ \\
\hline Total & 71 & $100 \%$ \\
\hline & & \\
\hline
\end{tabular}

Table 8: Frequency distribution of study subjects with other symptoms associated with OSMF.

\begin{tabular}{|c|c|c|}
\hline Symptoms & Number & $\%$ \\
\hline Ulceration & 54 & $76.10 \%$ \\
\hline Leathery texture & 4 & $5.50 \%$ \\
\hline Burning sensation & 10 & $14.10 \%$ \\
\hline All & 3 & $4.30 \%$ \\
\hline Total & 71 & $100 \%$ \\
\hline
\end{tabular}

\section{Discussion}

Research from developed countries, and also from India, suggests that multiple social, psychosocial (perceptions, knowledge, intentions) and environmental determinants influence the onset and progression of tobacco use during adolescence. These proximal and distal influences lead to higher use of tobacco products among youth belonging to low socioeconomic status (SES). Tobacco use in this group is also influenced by individual, cultural-environmental and social-contextual factors. 


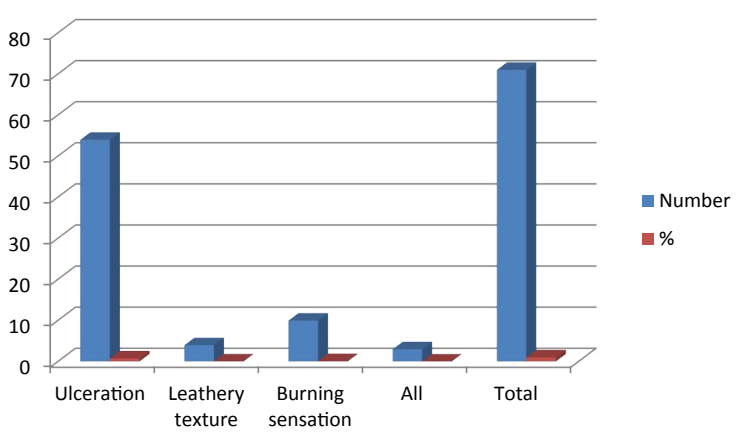

Figure 6: Bar Chart showing the occurrence of other symptoms associated with OSMF among the study subjects.

Table 9: Pearson's correlation between tobacco habit and the oral sub mucous fibrosis.

\begin{tabular}{|c|c|c|c|c|c|}
\hline Habits & Ulceration & $\begin{array}{c}\text { Leathery } \\
\text { texture }\end{array}$ & $\begin{array}{l}\text { Burning } \\
\text { Sensation }\end{array}$ & All & Total \\
\hline Smoking & $12(70.6 \%)$ & $2(11.8 \%)$ & $3(17.6 \%)$ & 0 & 17 \\
\hline Chewing & $13(76.5 \%)$ & 0 & $2(11.8 \%)$ & $2(11.8 \%)$ & 17 \\
\hline Snuffing & $1(20.0 \%)$ & $1(20.0 \%)$ & $3(60.0 \%)$ & 0 & 5 \\
\hline $\begin{array}{c}\text { Smoking \& } \\
\text { chewing }\end{array}$ & $26(81.25 \%)$ & $2(6.25 \%)$ & $2(6.25 \%)$ & $2(6.25 \%)$ & 32 \\
\hline Total & $52(73.24 \%)$ & $5(7.04 \%)$ & $10(14.08 \%)$ & $4(5.63 \%)$ & $71(100 \%)$ \\
\hline \multirow{2}{*}{$\begin{array}{l}\text { Pearson's } \\
\text { Correlation }\end{array}$} & \multicolumn{5}{|c|}{$r=-.124$} \\
\hline & \multicolumn{5}{|c|}{$\mathrm{p}=0.305(\mathrm{NS})$} \\
\hline
\end{tabular}

Prevention through early intervention during adolescence is required before it becomes an addiction. Tobacco prevention and cessation programmes for such youth need to address multiple individual and contextual risk factors in order to be effective.

It is essential to obtain the perspectives of youth and adults residing in disadvantaged settings with respect to the determinants of tobacco use. Project Advancing Cessation of Tobacco in Vulnerable Indian Tobacco Consuming Youth an activity funded by the Fogarty International Centre at the National Institutes of Health, USA, is a communitybased, group randomized intervention trial focused on disadvantaged youth (10-19 years) residing in 14 low-income communities (slums and resettlement colonies) in Delhi, India. Seven communities were randomly assigned to receive a 2-year intervention, while other seven communities served as the control group (and received free eye care and dental care).

Gupta et al. [11] suggested that the incidence of oral premalignant and malignant lesions is on the rise due to an increased number of people taking in tobacco and alcohol related habits. The concept of certain precancerous lesions proceeding into oral cancer has long been accepted. This was in accordance with the present study where $76.1 \%$ noted oral changes after the consumption of tobacco products.

According to the study conducted by Kumar and Muniyandi [12] in India, it was seen that tobacco is most commonly smoked in the form of cigarettes or bidis. This was similar to the present study where smoking was predominant (23.6\%). Evidence suggests that in India, tobacco use starts in childhood and adolescence, sometimes as early as 10 years old, and therefore, this vulnerable group should be especially targeted in tobacco control programs.

Makwana et al. [13] in their study on tobacco consumption habits among adolescents suggested that majority $66.23 \%$ had chewing habit exclusively, $14.61 \%$ smoked exclusively, and $19.16 \%$ had both smoking and chewing habits. In our study, it was observed that smoking habit was among $17(23.6 \%)$ chewing $18(25 \%)$, snuffing $6(8.4 \%)$, and smoking \& chewing among 30 (43\%).

Limitations of the present study can be attributed to the misrepresentation of female participants as they were very few in number. And also inclusion of a larger sample size could have enhanced generalization of results.

\section{Conclusion}

Tobacco consumption can be observed among the slum dwellers of Bhopal city and along with other factors, this factor too imparts an effect on the occurrence of OSMF in this population group. Further research into the other factors that have a synergistic effect on the disease is essential.

\section{References}

1. Silverman S Jr (2001) Demographics and occurrence of oral and pharyngeal cancers. The outcomes, the trends, the challenge. J Am Dent Assoc 132: 75-165.

2. Lane PM, Gilhuly J, Whitehead P, Zang H, Poh CF, et al. (2006) Single device for the direct visualisation of oralcavity tissue fluorescence. J Biomed Opt 11: 024006 .

3. Myers JN, Elkins T, Roberts D, Byers RM (2000) Squamous cell carcinoma of the tongue in young adults: increasing incidence and factors that predict treatment outcomes. Otolaryng Head Neck 122: 44-518.

4. Sherry LP, Jolanta AJ (2008) Oral cancer and cultural factors in Asia. Can J Dent Hygiene 42: 291-295.

5. Bhatt AP, Dholakia HM (1977) Mast cell density in oral submucous fibrosis. $J$ Indian Dent Asso 49: 187-191.

6. Bhosle RB, Murti PR (1985) Malignant transformation in OSMF over 17 year period. Comm Dent Epidem 13: 340-345.

7. Axell T, Pindborg JJ, Smith CJ, Van Der W (1996) Oral white lesions with special reference to precancerous and tobacco related lesions. Conclusions of International J Oral Path Med 25: 49-54.

8. Pindborg JJ, Murti PR (1984) Oral submucous fibrosis as a precancerous condition. Scan J Dent Res 92: 224-229.

9. Khanna S, Karjodkar FR (2004) National survey on oral carcinoma and tobacco abuse: The Indian Scenario. J Indian Acad Oral Med Radiol 16: 159.

10. Dangi J, Kinnunen TH, Zavras Al (2012) Challenges in global improvement of oral cancer outcomes: findings from rural Northern India. Tob Induc Dis 10: 5.

11. Gupta PC, Bhonsle RB, Murti PR, Daftary DK, Mehta FS, et al. (1989) An epidemiological assessment of cancer risk in oral precancerous lesions in India with special reference to nodular leukoplakia. Cancer 63: 2247-2252.

12. Kumar S, Muniyandi M (2015) Tobacco use and Oral Leukoplakia: Cross sectional study among the Gond tribe in Madhya Pradesh. Asian Pac J Cancer Prev 16: 1515-1518.

13. Makwana NR, Shah VR, Yadav S (2007) A study on prevalence of Smoking and Tobacco chewing among Adolescents in rural areas of Jamnagar District, Gujarat State. JMSR 1: 47-50. 